utilise twenty races for obtaining the common racial mean. His method of discussion is based on the safe ground that, if racial variability be associated with individual variability, whenever any specified character is more variable than another specified character in the one, it will (on the whole) be more variable in the other also. Therefore if the reduced quartiles of the two characters, in the series of means of races, be called $A$ and $B$. and those in that of the individuals of any given race be called $a$ and $b$, then if $\mathrm{A}$ be greater than $a, \mathrm{~B}$ would (on the whole) be greater than $\dot{b}$, and conversely. More briefly and fully, if the signs of the differences (A-B) and $(a-b)$ are alike, the evidence, so far as it goes, favours the suggested idea of a connection between racial and individual variability; if the signs are different it discountenances it.

The test is rough, but is of value when applied on a considerable scale with concurrent results, as in the present instance. The eighteen characters admit of $\frac{1}{2}(18 \times 17)=153$ different pairs of combinations of the form $(a-b)$, in each of the eight races; that is I224 pairs in all. Each of these has been compared with its associated pair in the series of means of races, of which there are altogether $\frac{1}{2}(8 \times 7)=28$. The result is that in seven out of the eight races the cases testifying to the existence of the suggested association are from twice to thrice as numerous as the others, and in the eighth race they are $\mathrm{I} \frac{1}{2}$ times as numerous. Nay more, there is some evidence that the most variable characters in the one, are the most variable in the other. This conclusion is corroborated by three other inquiries of the same kind, two into rodents and one into carnivoræ. The erro introduced by the strained assumption, that the ordinary law of frequency holds good for the series of means of allied races, does not seem likely to invalidate the general conclusion to a serious extent. It therefore appears that Mr. Brewster has provisionally established his thesis that whenever any specified character varies much in individuals of the same race, it is probable that it will be found to vary much in "allied" races, and conversely.

\section{ON THE CONSTITUTION OF THE ELECTRIC} SPARK. ${ }^{1}$

IF a Leyden jar is discharged through metal electrodes, and the spectrum of the spark is examined, it is found that the metallic lines are not confined to the immediate neighbourhood of the poles, but are seen sometimes in the centre of the spark, several millimetres away from the electrodes, from which they must have been projected with considerable velocity.

It has always seemed to me to be a problem of interest, to measure the velocity of projection. A knowledge of it may teach us something concerning the mechanism of electric sparks and, in addition, we may hope to obtain information on some important points in spectrum analysis, which are at present under discussion. Thus, for instance, if the speed with which a molecule is pushed forward into the centre of the spark depends on molecular weight, we may separate from each other those lines of the spectrum which belong to different molecular combinations. For many years past I had made various unsuccessful attempts to deal with this problem, when I became acquainted with the elegant method, used by Prof. Dixon in some of his recent experiments, in which a photograph is taken on a film fixed to the rim of a rapidly revolving wheel, of which the speed may easily be made sufficiently large to measure velocities of moving luminous particles up to 2000 metres. This number might be doubled or trebled with improved appliances.

The experiments were conducted by Mr. Gustav Hemsalech, to whose care and skill their success is largely due. Without entering into a detailed description of the apparatus, it will be sufficient to say that the photographs, which I now submit to the Section, were taken on a film moving with a linear speed of about $80 \frac{\text { metres }}{\text { second }}$ in a direction at right angles to the slit of the spectroscope. The lines of the metal appear inclined instead of straight, in consequence of the finite velocity of the luminous molecules. The air lines, on the other hand, though slightly broadened, remain straight. The sparks were taken from five large Leyden jars, charged by means of a Voss machine. Each

1 By Prof. Arthur Schuster, F.R.S. (Read before Section A of the British Associaticn at the 'J'oronto meeting )

NO. I 462 , VOL. 57$]$ single spark produces a good spectrum, reaching approximately from $\lambda=5000$ to $\lambda=4000$

One of the photographs, in which zinc poles were used, shows that the velocity of the molecules is gradually diminishing as they move away from the pole.' Close to it the speed seems very great, the average velocity up to a distance of about one millimetre being about 2000 metres per second. At a distance of four millimetres the speed is reduced to something like 400 .

In another experiment one pole was zinc, while the other was bismuth. Some bismuth lines are found to be decidedly more curved than those of zinc, indicating a smaller velocity. But the line of bismuth, which lies at 4560 , seems almost straight.

When the poles are moistened with a solution of calcium chloride interesting results are obtained, the calcium line at 4226 being more inclined than $\mathrm{H}$ and $\mathrm{K}$.

The experiments were made with comparatively rough appliances, but a more perfect apparatus is in course of construction; and the author hopes to continue the research in conjunction with Mr. Hemsalech.

\section{PHYSTOLOGY AT THE BRITISH ASSOCIATION.}

THE section of Physiology at the British Association meeting at Toronto was a large and active one. Under the presidency of Prof. Michael Foster a large body of physiologists attended in about equal numbers from the east and west of the Atlantic. Meetings were held on the Thursday and Friday, August 19 and 20 , and on the Monday, Tuesday and Wednesday, August 23, 24 and 25 .

Among those present were Messrs. Bowditch, Boyce, Cushny, Crookshank, Gaskell, IFalliburton, Huber, Huerthle, Lee, Loeb, Lombard, Billings, Lister, Macallum, Osler, Wesley Mills, Noël Paton, Porter, Waymouth Reid, Sherrington, G. N. Stewart, Anderson Stuart, Kellog, W. H. Thompson, Charles Richet, Waller, Welby, Shore, MacAlister, O. Grunbaum, Baldwin, Braun, Reynolds Green, Meldola, and A. S. Grunbaum.

Prominent among proceedings in the Section were the follow-

Prof. Bowditch read a paper on the physiology of unstriped muscular tissue as exemplified in the wall of the stomach of the frog. The rhythmic contractility of the tissue is well seen. When the organ or a strip of it is fitted to a recording apparatus, in the majority of instances after a lapse of not more than three hours, contractions of rhythmic recurrence are registered. Often two or more sets of rhythmic contractions are superposed. This may be best accounted for by supposing the musclecells to contract not all together but in tivo or more groups. In the discussion Prof. Sherrington referred to experiments published by him in which had been recorded contractions of the urinary bladder removed from freshly-killed monkeys and placed in warm normal saline solution, while connected with a volume recorder. In these the isolated bladder began to "beat" almust at once, and continued "beating" for an hour or less, at rate somewhat quicker than once a minute. The contractions thus obtained from the viscus only exceptionally displayed the compound character shown in Prof. Bowditch's curves.

Prof. Carl Huber brought forward observations on the cells of the sympathetic system of vertebrates. In Amphibia nearly all sympathetic cells are unipolar. In other vertebrates the prevailing type is multipolar. All sympathetic neurons have one axon only. The dendrites form a network between the cellbodies of the neurons constituting a ganglion. The axon of each sympathetic nerve-cell becomes either a non-myelinated nerve-fibre (grey fibre) or a fine myelinated nerve-fibre. The fibres of the white rami are axons of cells lying within the spinal cord, and these axons reach the sympathetic ganglia through the white rami, and in the ganglia undergo branching, ending in baskets which enclose the perikarya of the sympathetic neurons. In mammalia and birds the circumcellular baskets are comparatively simple networks of varicose fibrillæ. In Reptilia and Amphibia instead of simple end baskets the fibre is spirally wound and completely contorted. This is the explanation of Beale's spiral fibre in the sympathetic cells of the frog figured by him forty years ago. In all vertebrates the pericellular baskets are intracapsular. Langley and his pupils have shown that an impulse travelling along a spino-sympathetic efferent chain may be blocked in a sympathetic ganglion by the injection of nicotin. This has been applied to practically all regions of the 